\title{
Thermal reactions of aromatic hydrocarbons in the pyrolysis of ethane and propane
}

\author{
Roman Dimitriu* and Flavian Cuiban \\ Chemistry Department, Oil and Gas University of Ploiesti, \\ Bd. Bucuresti 39, Ploiesti, RO-2000, Romania \\ E-mail: ibolocan@mail.upq-ploiesti.ro
}

In memoriam C. D. Nenitzescu on the occasion of his $100^{\text {th }}$ birthday

(received 16 Jul 2001; accepted 14 Apr 2002; published on the web 22 Apr 2002)

\begin{abstract}
The influence of aromatics on the pyrolysis of ethane and propane was studied using benzene, toluene, $\alpha$-methylnaphthalene and anthracene as model compounds. The experiments were performed in a tubular flow reactor at ordinary pressure, temperatures of $700-850^{\circ} \mathrm{C}$, residence times between $0.1-1 \mathrm{~s}$ and low concentration of aromatics (1-6\%mole). Aromatic hydrocarbons inhibited the pyrolysis rate of ethane and propane and the following order of inhibitory effect which decreases with the increase of temperature - was found: toluene $>\alpha$-methylnaphthalene $>$ benzene $>$ anthracene. The $\mathrm{C}_{1}-\mathrm{C}_{4}$ composition of the effluent was only slightly influenced by the presence of aromatics, which were found to suffer an appreciable transformation to alkylated derivatives, depending on their structure and despite their thermal stability when highly diluted with $\mathrm{N}_{2}$ at the same temperatures. The transformation of the aromatic hydrocarbons was explained by the interference of the main chain propagators $\left(\cdot \mathrm{H}, \cdot{ }^{\cdot} \mathrm{CH}_{3},{ }^{\cdot} \mathrm{C}_{2} \mathrm{H}_{3},{ }^{\cdot} \mathrm{C}_{2} \mathrm{H}_{5}\right)$ with the aromatic and benzyl type radicals. Benzene has only a small contribution to soot formation, a phenomenon which however was found to increase when alkylaromatic and polycyclic hydrocarbons are present in the feed.
\end{abstract}

Keywords: Pyrolysis, aromatic hydrocarbons, radicals, ethane, propane

\section{Introduction}

Industrial pyrolysis of alkanes in order to obtain low olefins is always performed in the presence of variable quantities of aromatic hydrocarbons, which can originate from the feed and/or from secondary pyrolytic reactions. The mechanism and kinetics for the pyrolysis of individual alkanes $^{1}$ or aromatic hydrocarbons ${ }^{2}$ are well known and previous studies on the behavior of 
aromatic hydrocarbons in complex mixtures of alkanes ${ }^{3-5}$ or in the presence of hydrogen, methane and water ${ }^{6}$ focused mainly on coke formation.

The aim of this study is to clarify the influence of the individual aromatic hydrocarbons in the pyrolysis of ethane and propane, whose particular thermal decomposition mechanism is already well known. ${ }^{5}$ In this way, it is possible to assess the relative reactivity of benzene, toluene, $\alpha$-methylnaphthalene and anthracene, used as models for aromatic hydrocarbons, with the main chain radical propagators $\left(\cdot \mathrm{H}, \cdot \mathrm{CH}_{3}, \cdot \mathrm{C}_{2} \mathrm{H}_{3}, \cdot \mathrm{C}_{2} \mathrm{H}_{5}\right)$, which are typical for the elementary consecutive or parallel reactions taking place in the thermal cracking of alkanes. Hence, the pyrolysis of ethane and propane in the presence of small quantities of aromatic hydrocarbons $(1-6 \% \mathrm{~mol})$ was studied, in order to acquire new knowledge about the interference of alkane pyrolysis with aromatic hydrocarbons.

\section{Results and Discussion}

Our preliminary attempts revealed that the aromatic hydrocarbons we took as a model do not suffer perceptible change by heating them in nitrogen atmosphere $(95 \%)$ at the temperature used for alkane pyrolysis; only a slight toluene dealkylation $(0.5 \%)$ was observed for high temperature and long reaction time, as opposed to the transformation of benzene and toluene which take place without using an inert gas dilution, when diphenyl and diphenylethane were formed. The yields in low hydrocarbons $\left(\mathrm{C}_{1}-\mathrm{C}_{4}\right)$ were only slightly influenced by the presence of aromatic hydrocarbons in the pyrolysis of ethane and propane. Only the ethane yield was slightly increased in the case of propane pyrolysis with benzene or toluene, as it can be observed from figure 1.

We reported previously similar results, ${ }^{7}$ stating that the presence of aromatic hydrocarbons brings a slight increase in the amount of methane and $\mathrm{C}_{4}$ compounds, simultaneously with a decrease in the ethylene yield. Ethane and propane pyrolysis is inhibited by the presence of aromatic hydrocarbons, depending on the type of aromatics, their concentration and temperature. The inhibitor effect is stronger for alkylated aromatic hydrocarbons and may be quantitatively appreciated for ethane from the experimental results using the length of the radicalic chain (CL), calculated as follows: ${ }^{1}$

$$
\mathrm{CL}=\frac{\left[\mathrm{C}_{2} \mathrm{H}_{4}\right]-\left[\mathrm{CH}_{4}\right]}{\left[\mathrm{CH}_{4}\right]} \quad \text { as it can be noticed from table } \mathbf{1}
$$


Table 1. Reaction chain length in copyrolysis of ethane with aromatic hydrocarbons (3\%mole) at $800^{\circ} \mathrm{C}$ and $50 \%$ ethane conversion

\begin{tabular}{l|ccccc}
\hline $\begin{array}{l}\text { Feed } \\
\text { Chain }\end{array}$ & Ethane & $\begin{array}{c}\text { Ethane }+ \\
\text { toluene }\end{array}$ & Ethane $+\alpha$-methylnaphthalene & $\begin{array}{c}\text { Ethane }+ \\
\text { benzene }\end{array}$ & $\begin{array}{c}\text { Ethane }+ \\
\text { anthracene }\end{array}$ \\
\cline { 2 - 6 } $\begin{array}{l}\text { length } \\
\text { (CL) }\end{array}$ & 13 & 4.5 & 5.5 & 8.1 & 13 \\
\hline
\end{tabular}

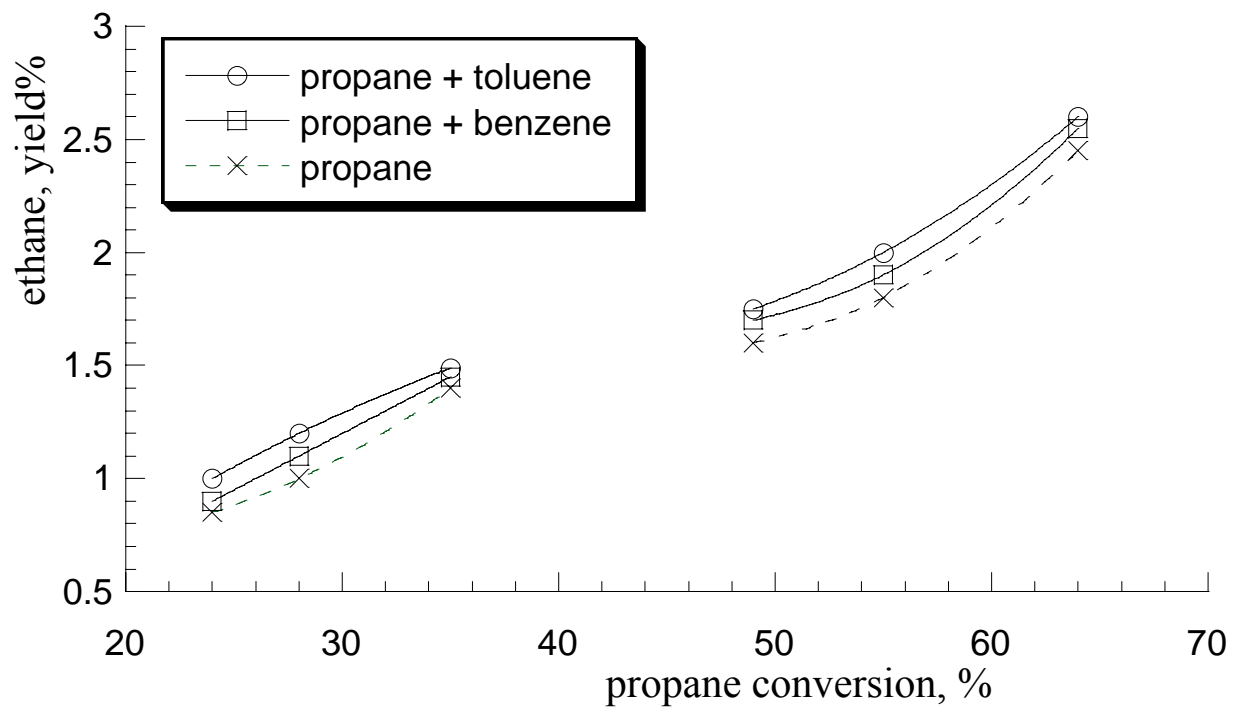

Figure 1. Yield of ethane dependent on propane conversion at propane and propane-toluene pyrolysis.

The inhibitor effect of benzene or toluene on the pyrolysis of propane cannot be evaluated in the same way but it can be appreciated by following the conversion decrease (figure 2).

The addition of benzene or toluene in the pyrolysis of ethane or propane determines an obvious change in the composition of the effluent liquid fraction. Thus, in the pyrolysis of propane alone, the aromatic hydrocarbons (benzene, toluene, ethylbenzene or styrene) are either absent or they are formed only in very small quantities and only at high conversions, while for the pyrolysis of propane with added benzene or toluene, aromatics are formed in significantly higher quantities, as it can be noticed in figures 3 and $\mathbf{4}$. 


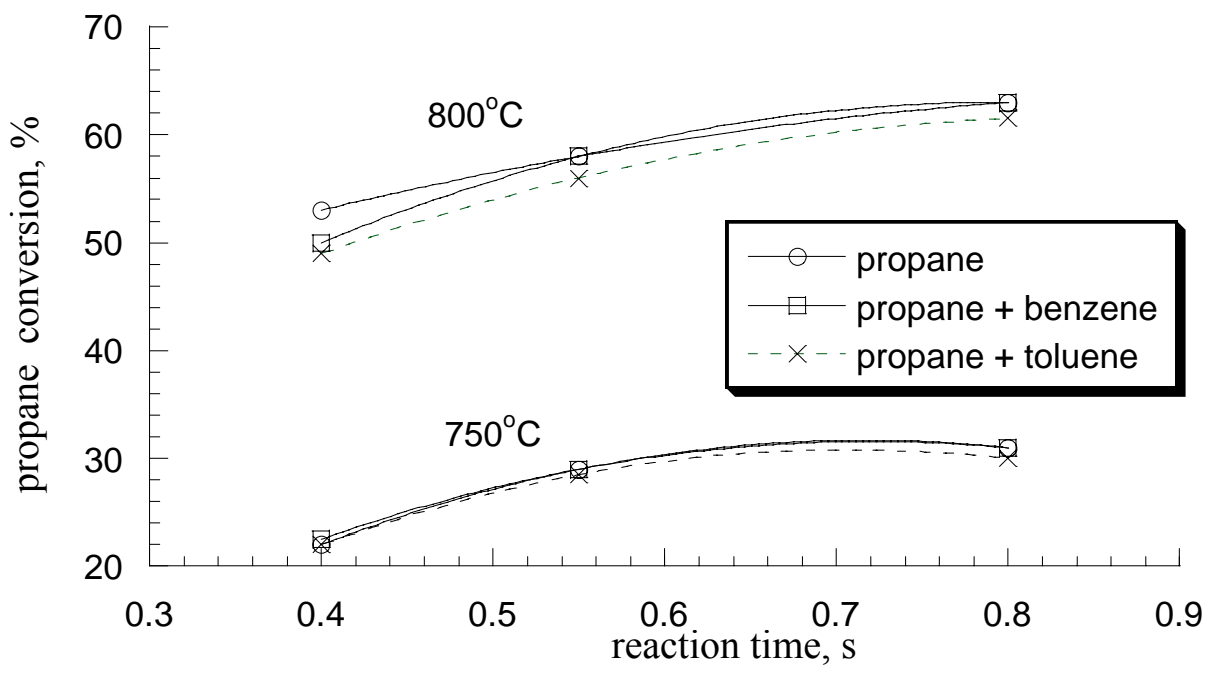

Figure 2. Propane conversion dependent on reaction time at propane and propane-benzene (toluene) pyrolysis.

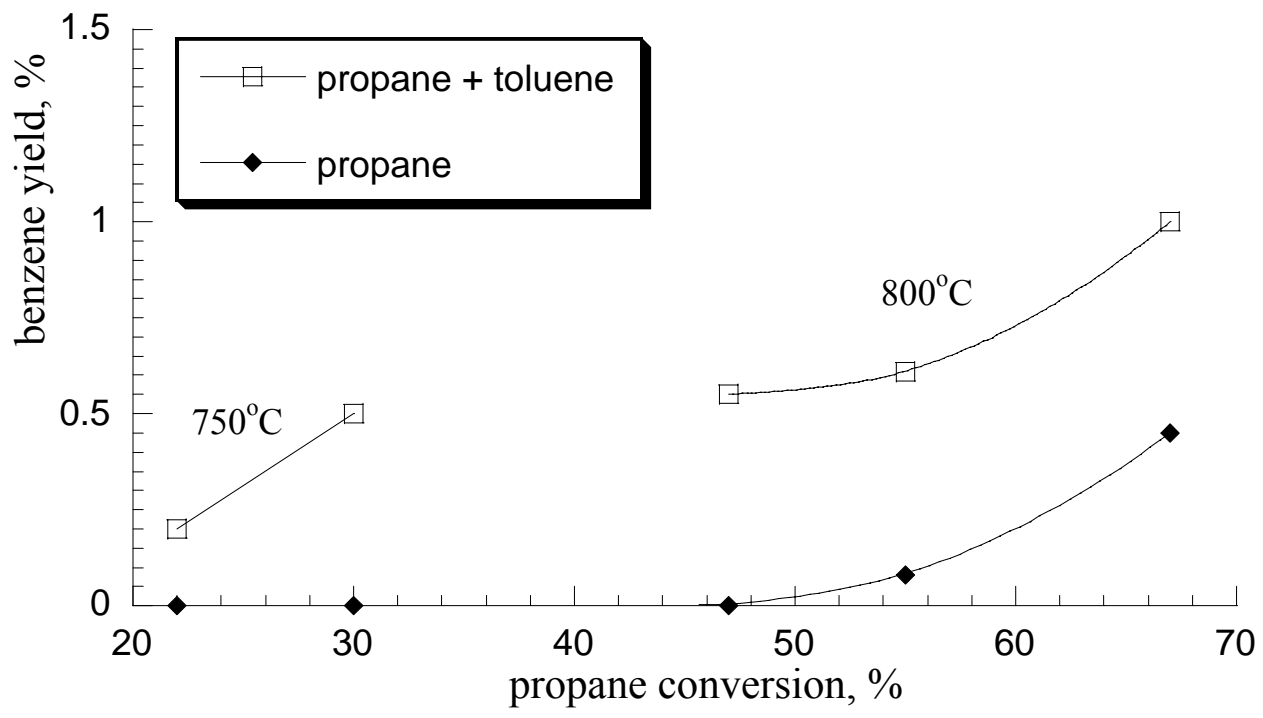

Figure 3. Yield of benzene dependent on propane conversion at propane and propane-toluene pyrolysis. 


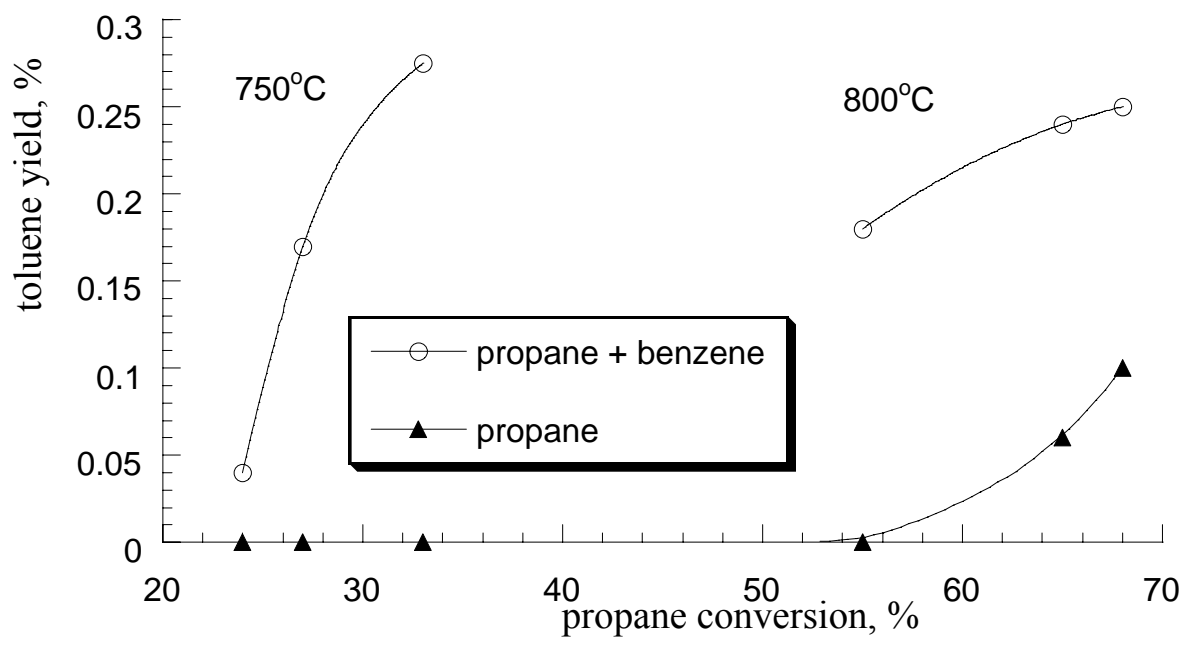

Figure 4. Yield of toluene dependent on propane conversion at propane and propane-benzene pyrolysis.

It is worthwhile to notice that for the pyrolysis of ethane in the presence of toluene, its conversion to other products was as low as $13.7 \%$, much smaller in comparison with the pyrolysis of propane with added toluene (32\% conversion). The yield of individual aromatic hydrocarbons in these two cases are significantly different: for the pyrolysis of ethane-toluene mixture, the benzene yield is $8.3 \%$, while for the pyrolysis of propane-toluene mixture is only $0.6 \%$. The yield of higher aromatic hydrocarbons in case of the propane-toluene mixture is much greater than for the ethane-toluene pyrolysis, as shown in table 2.

The much greater interference of toluene than that of benzene in the propane pyrolysis can be observed in table $\mathbf{3}$, which shows the changes in composition of the main aromatic hydrocarbons, depending on the pyrolysis temperature. 
Table 2. The composition of liquid fraction (\%wt) at ethane-toluene compared to propanetoluene pyrolysis

\begin{tabular}{ccc}
\hline $\begin{array}{c}\text { Feed } \\
\text { Products }\end{array}$ & Ethane + toluene & Propane + toluene \\
\hline benzene & 8.3 & 0.6 \\
toluene & 86.3 & 69.0 \\
others & 5.4 & 30.4 \\
\hline
\end{tabular}

Table 3. The composition of aromatic hydrocarbons fraction $(\% \mathrm{wt})$ at the pyrolysis of propane with benzene and toluene ( $6 \%$ mole) and different temperatures

\begin{tabular}{ccccccc}
\hline \multirow{2}{*}{ Feed } & \multicolumn{3}{c}{ Propane + toluene } & \multicolumn{3}{c}{ Propane + benzene } \\
\cline { 2 - 7 } Products & $780^{\circ} \mathrm{C}$ & $800^{\circ} \mathrm{C}$ & $825^{\circ} \mathrm{C}$ & $780^{\circ} \mathrm{C}$ & $800^{\circ} \mathrm{C}$ & $825^{\circ} \mathrm{C}$ \\
\hline Benzene & 0.94 & 5.70 & 4.50 & 93.50 & 85.20 & 83.90 \\
Toluene & 81.40 & 78.10 & 68.10 & 3.50 & 5.00 & 6.07 \\
o-xilene & 4.39 & 3.30 & 3.66 & - & - & - \\
ethylbenzene & 4.19 & 4.00 & 4.40 & 0.20 & 0.50 & 0.50 \\
Styrene & 2.20 & 3.10 & 6.80 & 1.70 & 6.20 & 7.00 \\
methyl styrene & 0.57 & 0.94 & 2.70 & - & - & - \\
propyl benzene & 0.47 & 0.39 & 0.41 & - & - & - \\
napththalene & 1.54 & 1.55 & 3.90 & 0.20 & 0.20 & 1.00 \\
Biphenyl & - & - & - & - & - & 0.03 \\
Others & 4.29 & 2.92 & 5.20 & 0.90 & 2.90 & 1.50 \\
\hline
\end{tabular}

The benzene concentration in the aromatic fractions resulted from the pyrolysis of propanetoluene mixtures is 2 to 5 times greater than that of toluene resulted from the pyrolysis of propane-benzene mixtures (compare figures 3 and 4). Apart from the reciprocal toluene-benzene transformation, it is to underline that the conversion of benzene to other aromatic hydrocarbons changes between $6-16 \%$, dependent on the process conditions, while the toluene conversion (in similar conditions) is much higher, about 19-23\%. Monocyclic alkylaromatics (and not polycyclic) prevail in the liquid fraction. It is worthwhile noticing the composition change in ethylbenzene and styrene; also, the absence of diphenyl and dibenzyl must be underlined.

The absence of diphenyl and formation of only very small quantities of naphthalene and heavier aromatic compounds in the pyrolysis of ethane or propane in the presence of low amounts of benzene (3-6\%) is a conclusive proof that benzene does not significantly contributes to coke forerunners and, as a consequence, to the coke formation in low alkanes pyrolysis.

The inhibitor effect of the aromatic hydrocarbons in ethane and propane pyrolysis is manifested by the modification of product distribution, the decrease of chain radical length at ethane pyrolysis and the small decrease of conversion for propane pyrolysis, at equivalent reaction conditions. These facts could be explained by the interference of the aromatic 
hydrocarbons in the reaction mechanism for the ethane and propane pyrolysis; hydrogen atoms are the main chain radical propagator, but radicals such as $\mathrm{CH}_{3},{ }^{-} \mathrm{C}_{2} \mathrm{H}_{5},{ }^{\cdot} \mathrm{C}_{2} \mathrm{H}_{3}$ do also participate, perpetuating the radical state in the propane and higher alkanes pyrolysis. They participate in atom-extraction reactions, in $\beta$-type cleavage of $\mathrm{C}-\mathrm{C}$ or $\mathrm{C}-\mathrm{H}$ bonds or in recombination reactions which, for the aromatic hydrocarbons, may be mediated by $\pi$-electrons, such as reactions 1-4 are.

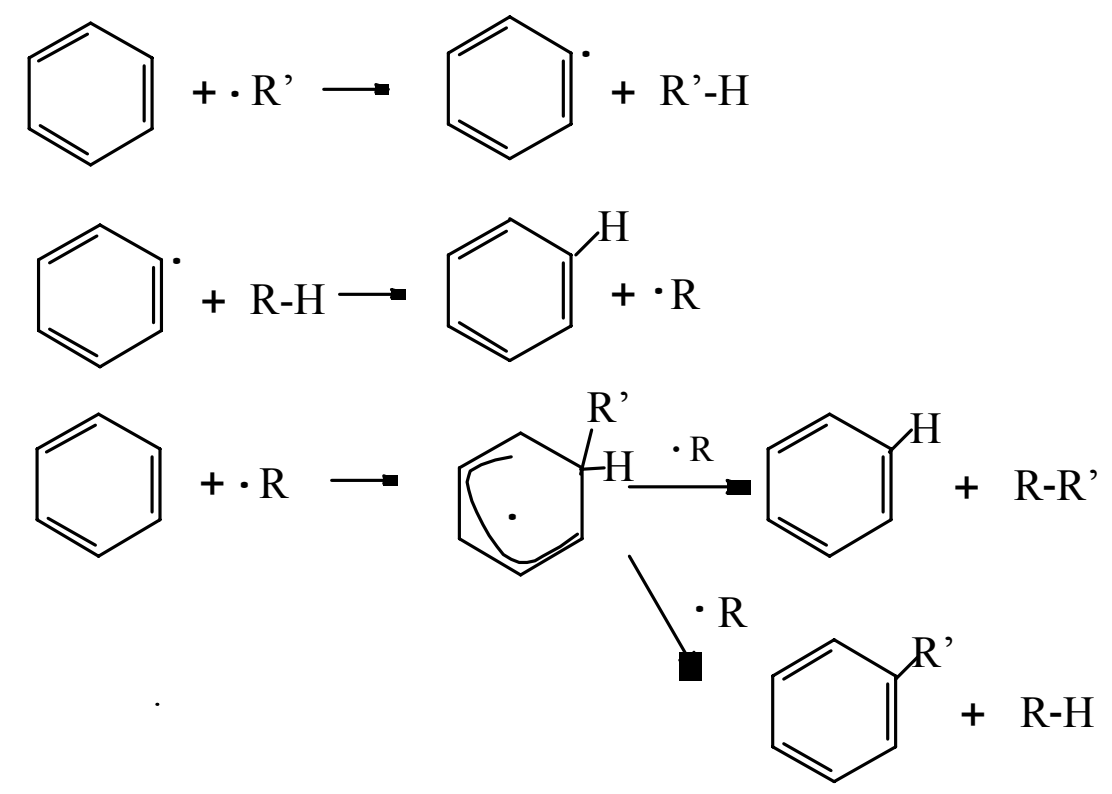

$\mathrm{R}$ and $\mathrm{R}^{\prime}$ are active radicals: $\cdot \mathrm{H}, \mathrm{CH}_{3}$, etc.

Phenyl and benzyl radicals are the main ones found in individual benzene and toluene pyrolysis and they lead to diphenyl, respectively to diphenylethane formation, besides variable amounts of heavier aromatic compounds with two or more aromatic rings. In the presence of ethane and propane, the small quantities of benzene or toluene which were found present generate mainly monocyclic alkylated aromatic hydrocarbons and only small quantities of naphthalene. Reactions $\mathbf{3}$ and $\mathbf{4}$ are mediated by aromatic cycles; they are chain termination reactions, therefore they inhibit the pyrolysis. The toluene yield in the propane-benzene pyrolysis, which is less dependent on the severity of the process (or on the conversion) than the $\mathrm{C}_{1}-\mathrm{C}_{4}$ hydrocarbons is similar to benzene yield in the propane-toluene pyrolysis (figure 3 ) and much lower than that of toluene in benzene-propane pyrolysis (table 2 and 3 ) suggests that, between the main chain propagators $\left(\cdot \mathrm{H}\right.$ and $\left.{ }^{\circ} \mathrm{CH}_{3}\right)$, reactions involving $\cdot \mathrm{H}$ radicals are developed to a greater extent. It means that reaction $\mathbf{5}$ (practically irreversible) is followed by $\mathbf{6}$ and its reversible reaction. Reaction 7, which is essentially the displacement of hydrogen atom from the aromatic cycle by another reactive radical, is the slowest reaction. These results are also in accordance with similar studies found in literature. ${ }^{8}$ 
The dissociation of toluene into the two very reactive radicals (reverse of reaction 8) requires a high amount of energy so that the concentration of the phenyl radicals produced in reaction 7 alone is very low.

$$
\begin{aligned}
& \mathrm{C}_{6} \mathrm{H}_{5} \mathrm{CH}_{3}+\cdot \mathrm{H} \longrightarrow \mathrm{C}_{6} \mathrm{H}_{5} \mathrm{CH}_{2} \cdot+\mathrm{H}_{2} \\
& \mathrm{C}_{6} \mathrm{H}_{5} \mathrm{CH}_{3}+\cdot \mathrm{H} \longrightarrow \mathrm{C}_{6} \mathrm{H}_{6}+\cdot \mathrm{CH}_{3} \\
& \mathrm{C}_{6} \mathrm{H}_{6}+\cdot \mathrm{CH}_{3} \longleftrightarrow \cdot \mathrm{C}_{6} \mathrm{H}_{5}+\mathrm{CH}_{4} \\
& \cdot \mathrm{C}_{6} \mathrm{H}_{5}+\cdot \mathrm{CH}_{3} \longleftrightarrow \mathrm{C}_{6} \mathrm{H}_{5} \mathrm{CH}_{3}
\end{aligned}
$$

Styrene and ethylbenzene can be theoretically obtained by propane-benzene or propane-toluene mixtures pyrolysis, through reactions 9-13; some of these reactions involve $\pi$ electrons of the aromatic nucleus:

$$
\begin{aligned}
& \mathrm{C}_{6} \mathrm{H}_{6}+\cdot \mathrm{C}_{2} \mathrm{H}_{5} \rightarrow \cdot \mathrm{H}+\mathrm{C}_{6} \mathrm{H}_{5} \mathrm{CH}_{2} \mathrm{CH}_{3} \stackrel{-\mathrm{H}_{2}}{\longrightarrow} \mathrm{C}_{6} \mathrm{H}_{5} \mathrm{CH}=\mathrm{CH}_{2} \\
& \mathrm{C}_{6} \mathrm{H}_{6}+\cdot \mathrm{C}_{2} \mathrm{H}_{3} \rightarrow \mathrm{C}_{6} \mathrm{H}_{5} \mathrm{CH}=\mathrm{CH}_{2}+\cdot \mathrm{H} \\
& \mathrm{C}_{6} \mathrm{H}_{5} \mathrm{CH}_{3}+\cdot \mathrm{R} \stackrel{-\mathrm{RH}}{\longrightarrow} \mathrm{C}_{6} \mathrm{H}_{5} \mathrm{CH}_{2} \cdot \stackrel{\cdot \mathrm{CH} 3}{\longrightarrow} \mathrm{C}_{6} \mathrm{H}_{5} \mathrm{CH}_{2} \mathrm{CH}_{3} \stackrel{-\mathrm{H}_{2}}{\longrightarrow} \mathrm{C}_{6} \mathrm{H}_{5} \mathrm{CH}=\mathrm{CH}_{2} \\
& \mathrm{C}_{6} \mathrm{H}_{5} \mathrm{CH}_{3} \stackrel{\mathrm{C}_{2} \mathrm{H}_{3}}{\longrightarrow} \cdot \mathrm{CH}_{3}+\mathrm{C}_{6} \mathrm{H}_{5} \mathrm{CH}=\mathrm{CH}_{2} \stackrel{\mathrm{H} 2}{\longrightarrow} \mathrm{C}_{6} \mathrm{H}_{5} \mathrm{CH}_{2} \mathrm{CH}_{3} \\
& \mathrm{C}_{6} \mathrm{H}_{5} \mathrm{CH}_{3} \stackrel{\cdot \mathrm{C}_{2} \mathrm{H} 5}{\longrightarrow} \cdot \mathrm{CH}_{3}+\mathrm{C}_{6} \mathrm{H}_{5} \mathrm{CH}_{2} \mathrm{CH}_{3} \stackrel{-\mathrm{H}_{2}}{\longrightarrow} \mathrm{C}_{6} \mathrm{H}_{5} \mathrm{CH}=\mathrm{CH}_{2} \\
& 2 \mathrm{C}_{6} \mathrm{H}_{5} \mathrm{CH}_{2} \cdot \rightarrow \mathrm{C}_{6} \mathrm{H}_{5} \mathrm{CH}_{2} \mathrm{CH}_{2} \mathrm{C}_{6} \mathrm{H}_{5} \\
& \cdot \mathrm{R}^{\prime}+\cdot \mathrm{R}+\mathrm{M} \rightarrow \mathrm{R}^{\prime}-\mathrm{R}+\mathrm{M}^{*}
\end{aligned}
$$

The absence of ethylbenzene from the effluent produced in the propane-benzene pyrolysis eliminates the assumption of styrene formation through reactions 9 or 11. The low yields of toluene obtained at propane-benzene pyrolysis represent a sign that, in this case, formation of styrene from benzene through reaction $\mathbf{1 1}$ is, to a certain extent, not important. Neither reaction 8 reaction between radicals, (phenyl - insignificant concentration) can have an important contribution to the formation of toluene. As a consequence, the main reaction for the formation of styrene in propane-benzene pyrolysis can only be reaction 10, with the participation of ${ }^{\circ} \mathrm{C}_{2} \mathrm{H}_{3}$ radical. In propane-toluene pyrolysis, both ethylbenzene as well as styrene are obtained (figures 5 and 6), but that does not exclude a priori any of the reactions 11-13. 


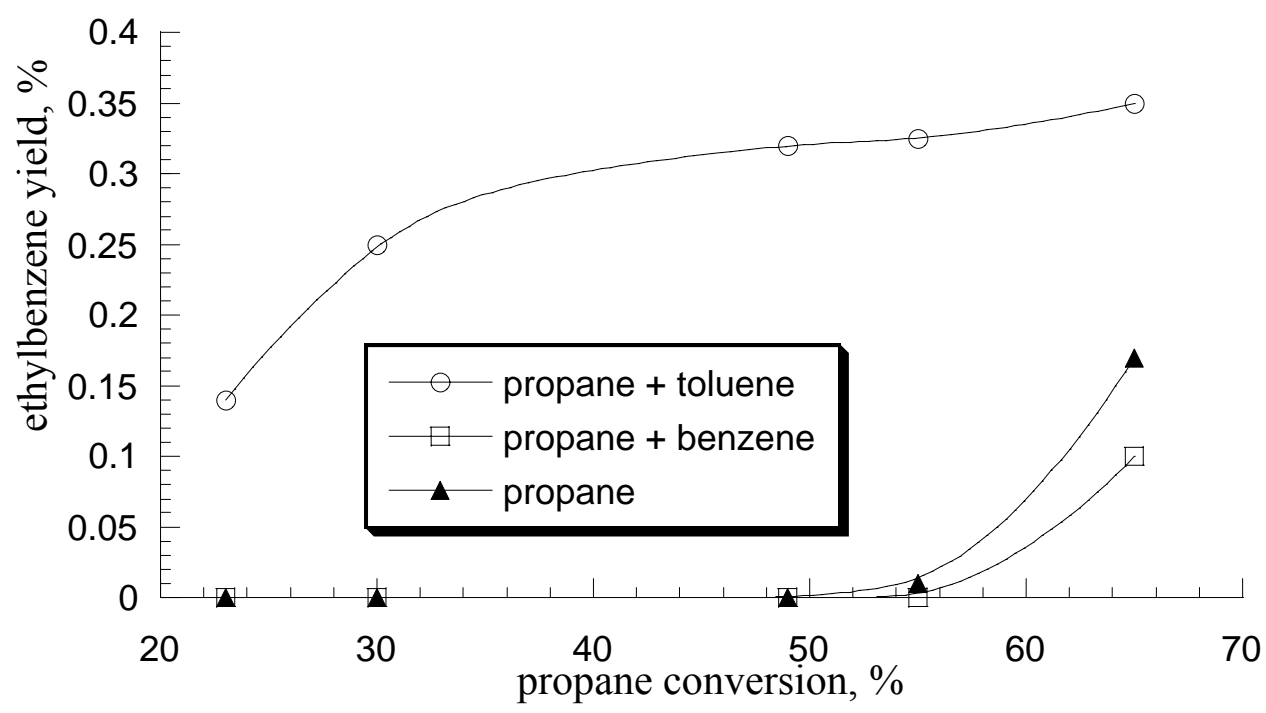

Figure 5. Yield of ethylbenzene dependent on propane conversion at propane and propanebenzene (toluene) pyrolysis.

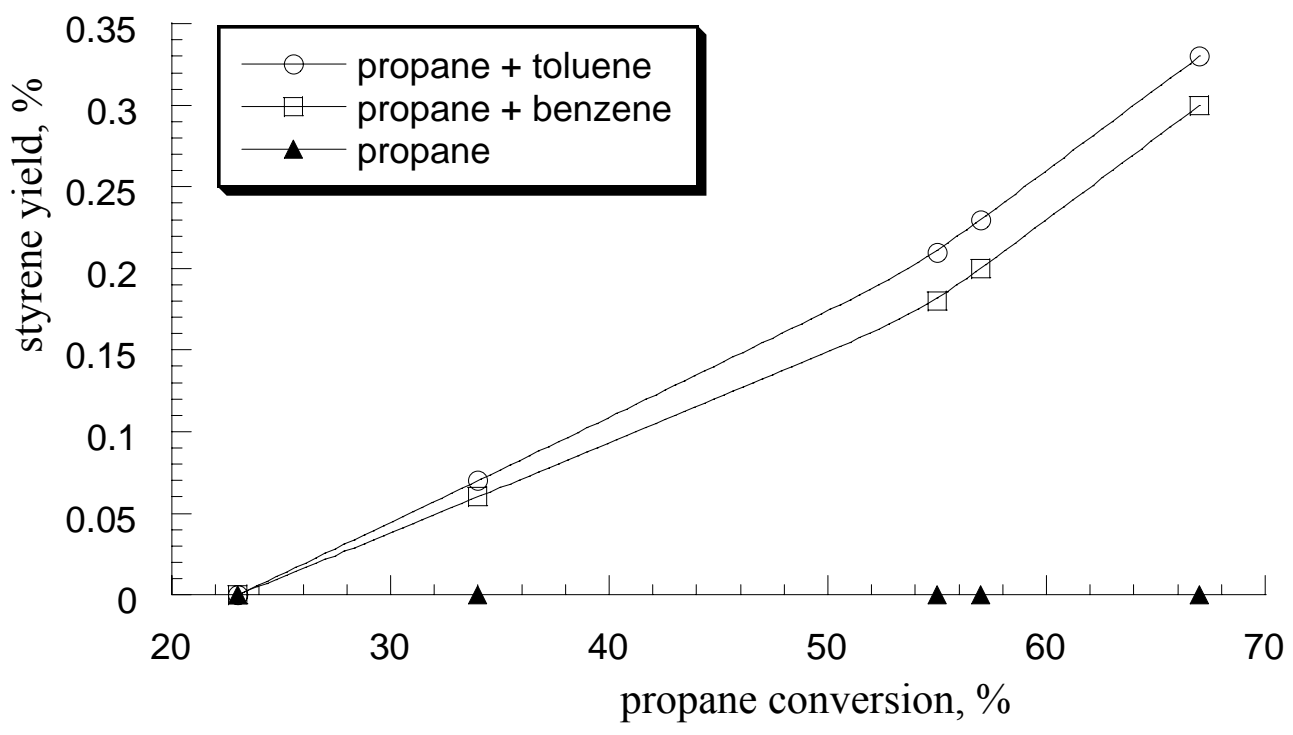

Figure 6. Yield of styrene dependent on conversion at propane and propane-benzene (toluene) pyrolysis. 
The ethyl radical does not take part in hydrogen exchange reactions with benzene through reaction 9 , because no ethylbenzene was found in the effluent and it cannot be obtained through reaction 13, by exchange with ${ }^{\circ} \mathrm{CH}_{3}$ (comparable as reactivity with $\cdot H$ ). Therefore, $\mathbf{1 1}$ and $\mathbf{1 2}$ are the main reactions in the formation of ethylbenzene and styrene. Absence of ethyltoluene from the effluent is also an additional argument for that. The inhibitor effect of toluene in the propane pyrolysis is of course explained by reaction 11, where ethylbenzene is generated by the recombination of the benzyl radical with the methyl one. The recombination is favored by the participation of the benzyl radical, which is relatively stable due to resonance and its size. The same explanation is valid for the formation of propylbenzene (table 3) in propane-toluene pyrolysis, by recombination of the benzyl radical with the ${ }^{\circ} \mathrm{C}_{2} \mathrm{H}_{5}$ radical. Reaction $\mathbf{1 4}$ is not important for the global mechanism because the presence of diphenylethane was not observed. Formation of ethylbenzene by hydrogenation of styrene (reaction 12) is less probable, because in the propane-benzene pyrolysis only styrene was found, but no ethylbenzene.

The inhibition of alkanes pyrolysis with aromatic hydrocarbons can be due to two reasons: a) the increasing rate of chain radical termination reactions as a consequence of formation and combination of benzyl type radical through reaction 11 , where $\cdot R$ is a chain radical propagator of alkane pyrolysis; $b$ ) intermediate capture of the chain radical propagator, due to the $\pi$ electrons of the aromatic nucleus and the takeover of the energy of recombination of two radicals with increased reactivity, such as ${ }^{\cdot} \mathrm{H}$ or ${ }^{\cdot} \mathrm{CH}_{3}$, through reactions $\mathbf{3}$ and $\mathbf{4}$. In these reactions, the radical capture leads to the formation of a cyclohexadienyl radical, which is more stable and that can react further on by bimolecular collision with the second chain propagator radical. In this way, the restricted condition of the three-molecules collision (reaction 15) is eliminated. The increased yield of ethane observed in benzene- or toluene-propane pyrolysis is just an extra proof of this behavior. The lowering of the inhibitory action of the aromatic hydrocarbons in alkanes pyrolysis at increased temperature is due to the reversibility of the reactions involved in the pyrolysis process. One can explain in this way the formation of $o$-xylene and propylbenzene in the propane-toluene pyrolysis, the naphthalene formation in ethane- $\alpha$-methylnaphthalene pyrolysis as well as the unaffected chain radical length in ethane-anthracene pyrolysis (due its high reactivity at 9 and 10 positions). It has to be emphasized that the presence of alkylated aromatic and polycyclic hydrocarbons in the alkanes pyrolysis has as a consequence a sensible increase in coke formation. Ethane and propane pyrolysis could be considered as models for the liquid alkanes pyrolysis and therefore the results obtained in studying the aromatic hydrocarbons influence on their pyrolysis may be extended to liquid fractions, where the complexity of the raw material does not allow to observe this influence. 


\section{Experimental Section}

Pure propane or propane-benzene (toluene) mixtures, $6 \%$ mole, with steam/hydrocarbon dilution of $1 / 1$ molar, were used for the experiments, which were performed in a steel reactor and conditions similar to those ones used in the industrial hydrocarbon pyrolysis. Reactor outlet temperatures were $750^{\circ} \mathrm{C}$ and $800^{\circ} \mathrm{C}$, the reactor total length $17.6 \mathrm{~m}$ and inner diameter $9 \mathrm{~mm}$. The reactor outlet pressure was maintained at 2 atmospheres for all experiments. Constructive particularities of the reactor did not allow major changes in the inlet flow rates, therefore the conversions obtained for propane varied between $23 \%$ and $33 \%$ for a reactor outlet temperature of $750{ }^{\circ} \mathrm{C}$, and between $50 \%$ and $65 \%$ for a reactor outlet temperature of $800^{\circ} \mathrm{C}$. Pyrolysis of benzene (toluene), $6 \%$ mole, in the presence of nitrogen, was experimented in a quartz reactor, at reaction times and temperatures comparable with those ones used for pyrolysis of propane with added benzene (toluene). Pyrolysis of ethane (propane) + benzene (toluene), $6 \%$ mole, or $\alpha$ methylnaphthalene and anthracene, 1-3\%mole, was performed at temperatures of 750, 800 and $825^{\circ} \mathrm{C}$ in a quartz reactor. For each experiment, the longitudinal temperature profile of the (either steel or quartz) reactor was determined, and then the "equivalent length" and "equivalent volume", corresponding to reference temperature by Hougen-Watson method, were calculated. All pyrolysis experiments were performed under dynamic conditions, at equivalent reaction time of 0.2-1.0 seconds. $\mathrm{C}_{1}-\mathrm{C}_{4}$ product yields were calculated according to the feed amount of ethane (propane); aromatic product yields are expressed as \%wt. of aromatic hydrocarbons in the cracked gas.

Details concerning reactors, analytical methods, operating procedures and reagents are presented in previously published papers. ${ }^{7,9}$

\section{Acknowledgements}

Thanks are given to Laboratorium voor Petrochemische Technik of Gent University - Belgium, for assistance to perform some experiments and analysis by GC-MS of the liquid hydrocarbon mixtures samples.

\section{References}

1. Zdonik, S.; Green, E.; Hallee, L. Manufactured Ethylene, The Petroleum Publishing Co., Oklahoma, 1971.

2. Badger, G. M. Pyrolysis of Hydrocarbons, Progr. Phys.Org.Chem. 1965, 3, 1.

3. Svob, V.; Deur-Siftar, D. J. Chromat. 1974, 91, 659.

4. Poutsma, M. A. Energy and Fuels 1990, 4, 113.

5. Qi, Chen.; Froment, G.F. J.Anal.Appl.Pyrolysis 1991, 21, part I, 27 and part II, 51. 
6. Jess, A. Fuel 1996, 75(12), 1441.

7. Dimitriu, R.; Albu, M.; Cuiban, F. Revista de Chimie 1987, 38, 765.

8. Robaugh, D.; Tsang, W. J. Phys. Chem. 1986, 90, 4159.

9. Dimitriu, R.; Ph.D. Thesis, Oil and Gas University of Ploiesti, 1996. 